\title{
ИССЛЕДОВАНИЕ СУЖДЕНИЯ О ФУНКЦИИ МУЗЫКИ В МУЗЫКАЛЬНОЙ МЫСЛИ СЮНЬ-ЦЗЫ
}

\section{INVESTIGATION OF THE JUDGMENT ON THE FUNCTION OF MUSIC IN THE MUSICAL THOUGHT OF XUN-TZU \\ Hou Yunlong}

Summary: Xun-tzu's musical thought advocates the use of music to guide people, to make them move from evil to good, which is somewhat different from Mencius's thoughts; advocates promoting military campaigns through music, so that «the army is strong, the cities are fortified, and the enemy does not dare to attack even a baby", which is somewhat different from the thoughts of Confucius; advocates for the interaction of ritual and music to govern people and country. His musical and aesthetic thought still belongs to the Confucian tradition. This article analyzes from a logical point of view the way of understanding the function of music in the musical thought of Xun-tzu. This proves that Confucian musical-aesthetic thought reached maturity only under Xun-tzu.

Keywords: Xun Tzu, ancient music of China, judgment.

\author{
Хоу Юньлун \\ Преподаватель, Педагогический университет \\ провинции Цзянси, провинция Цзянси, Китай \\ 13707098756@163.com
}

Аннотация: Музыкальная мысль Сюнь-цзы выступает за использование музыки для того, чтобы направлять людей, заставить их двигаться от зла к добру, что несколько отличается от мыслей Мэн-цзы; выступает за то, чтобы посредством музыки продвигать военные походы, чтобы «армия была сильной, города были укреплёнными, а враг не осмеливался напасть даже на младенца», что несколько отличается от мыслей Конфуция; выступает за взаимодействие ритуала и музыки для управления людьми и страной. Его музыкально-эстетическая мысль по-прежнему относится к конфуцианской традиции. В данной статье с логической точки зрения анализируется путь осмысления функции музыки в музыкальной мысли Сюнь-цзы. Это доказывает, что конфуцианская музыкально-эстетическая мысль достигла зрелости только при Сюнь-цзы.

Ключевые слова: Сюнь-цзы, древняя музыка Китая, суждение.
«C юнь-цзы» - это собрание сочинений Сюнь-цзы, состоит из 32 глав. В своей дискуссии о музыке он дает исчерпывающее и богатое объяснение характерных особенностей музыки, эстетического восприятия музыки, её социальных функций, эстетических критериев и других аспектов. В его образе мышления и точке зрения есть новаторство и развитие. Его дискуссия о музыкально-эстетической мысли в основном сосредоточена в «Юэ лунь», в других главах также содержатся разрозненные записи.

В настоящее время исследования Сюнь-цзы в основном отталкиваются от содержания его дискуссий. Считается, что он исходил из теории о «злой натуре», ориентируясь на идею Мо-цзы об «антимузыке», он делает акцент на «великий порядок в Поднебесной, эпоху нейтрализации» [4, с. 56], «если следовать пути наших предков, ритуалы и музыка будут процветать» [3, с. 211] и так далее. Однако исследования Сюнь-цзы с логической точки зрения немногочисленны. Данная статья направлена на анализ пути осмысления музыкальной мысли Сюньцзы с философской точки зрения и направления его суждений о музыкальной концепции.

Сюнь-цзы, мыслитель последнего периода эпохи Враждующих царств в Китае, жил примерно в 313-238 гг. до н. э. Его личное имя (мин) было Куан, уроженец государства Чжао, современники величали его по прозва- нию (хао) Цин. При династии Хань он скрывался и именовал себя Сунь Цин. Он подчеркивал: «вокальная музыка глубоко проникает в сердце человека и быстро преображает его» [2, с. 38], «изменяет старые обычаи и нравы» [10, с. 180], подтверждая роль музыки в нравственном воздействии на сердца людей и в формировании характера. Наша военная музыка подтверждает роль музыки в ходе войны. Кроме того, он также рассматривал связь между «музыкой» и «желанием» $[1$, с. 26], «музыкой» и «ритуалом» $[1$, с. 32]. Анализируя с логической точки зрения, Сюнь-цзы разделяет музыкальную концепцию на три звена: универсальное, особое и индивидуальное [9, с. 46], а также разделяет и дает определение внутренней концепции конфуцианской музыкальной мысли Конфуция и Мэн-цзы.

\section{1. ЕАИнство сужАений о взаимодействии "ритуала» и «музыки»}

Вступление к «Юэ лунь»: «Лэ означает радость. Это то, в чем нуждаются человеческие эмоции и не могут остановиться. Поэтому человек не может жить без радости, а радость непременно должна выражаться через звук, выражаться через движение. А человек является человеком постольку, поскольку изменения его мыслей и чувств выражаются в музыке и в танце. Поэтому человек не может жить без радости, а радость не может не быть выражена, а если она была выражена, но не направила 
людей, то это не может не повлечь за собой хаос. Наши предки ненавидели этот хаос, и поэтому они сочиняли изящную хвалебную музыку, чтобы направлять людей, и мелодии было достаточно, чтобы принести людям радость, но не развратить их, песен было достаточно, чтобы просветить людей, но не привести их ко злу, а изгибов или прямоты музыки, её сложности или простоты, тонкости или полноты, остановки или продолжения было достаточно, чтобы затронуть в людях добрые чувства, с тем, чтобы атмосфере зла было неоткуда приблизиться к людям. Вот принципы, в соответствии с которыми наши предки сочиняли музыку.» [5, с. 152] Очевидно, что суждение Сюнь-цзы о музыкальной концепции основано на особенностях музыкальной концепции. Он подробно изложил свой ход мыслей касательно музыки, показал различия между звеньями и их связь между собой. В его суждениях каждое звено концепции музыки считается отдельным звеном, «лэ», «радость», «музыка», «танец», «норма» [9, с. 330] - они одновременно тождественны сами себе, но не другим звеньям. Связь между ними проистекает из самой музыкальной концепции, потому что концепция в своей экстернализации имеет ту же природу, что и она сама. Будучи звеньями одной концепции, индивидуальность и универсальность нельзя изолировать друг от друга, то есть это не чётко установленные идентичность или универсальность [8, с. 324]. Поэтому суждение Сюнь-цзы о концепции музыки действительно своеобразно, то есть, его суждение - это формулировка различий музыкальных концепций или их положений, но такого рода различия все же могут сохранять свою универсальность [9, с. 187].

Когда он судит или оценивает музыку как объект, это основано не на его субъективном навязывании такого отношения к музыке, а на положениях самостоятельно возникшей в ходе его исследования концепции музыки [6, с. 78]. Он говорит: «Когда в храме предков играет музыка, и государь и министры совместно слушают её, то между ними не будет несогласия, а будет серьёзность; когда музыка играет в кругу семьи, и отцы и сыновья, старшие и младшие братья совместно слушают её, то не будет несогласия, а будет любовь; когда музыка играет в деревне, а мужчины и женщины, стар и млад слушает её, то не будет несогласия, а будет повиновение. Музыка - это выбор среднего звука в качестве основы для организации других звуков, чтобы музыка гармонично развивалась; это организация различных инструментов для выражения ритма; это комплексное исполнение различных мелодий для формирования части музыкального произведения. Поэтому её достаточно и для воплощения пути предков, и для того, чтобы показать различные изменения в обществе, чтобы оно в конце концов начало соответствовать пути предков. Вот причины, по которым наши предки сочиняли музыку.» [5, с. 136] Эти его разные суждения нельзя рассматривать как расположенные на одном уровне, имеющие одинаковую ценность, их сперва нужно рассматривать как формирующие последовательность этапов, а различия между суждениями построены на логическом значении музыкальной концепции $[6, c .84]$.

\section{2. Сужмение о змесь-сушествовании музыки}

Здесь-существование означает конкретное существование, это существование ограниченного текущего реального явления в определенное время, в определенном месте, имеющего определенное качество и количество [11 , с. 97]. В «Юэ лунь» говорится: «Когда слышишь изящные хвалебные мелодии наших предков, грудь расширяется; когда берешь в руки танцевальные реквизиты, такие как щиты и топоры, тренируешься наклоняться и подниматься, сгибаться и вытягиваться, облик приобретает торжественность; двигаешься взад и вперед в соответствии с рисунком танца и музыкой, движения соответствуют ритму музыки и танца, а манера держаться соответствует нормам этикета. Поэтому музыку за пределами страны можно использовать для пропаганды военных походов, в внутри страны - для пропаганды этикета. Значение военных походов и этикета одинаково: если осуществлять военные походы за пределами страны, то не будет непослушных, если внутри страны проявлять друг к другу вежливость, то не будет неповинующихся. Таким образом, музыка - это важный способ навести порядок в Поднебесной и объединить её, а характер сделать правильным и умиротворенным, это то, что нужно для человеческих эмоций и не может остановиться. Вот причины, по которым наши предки сочиняли музыку.» [5, с. 156] Это прямолинейное суждение является суждением о здесь-существовании. Суждение может быть положительным или отрицательным [8, с. 271]. С объективной точки зрения эти суждения выражают вещи, существующие в музыке или свойства чувственных явлений. С одной стороны, они становятся пустым тождеством, с другой стороны, они становятся отношениями, вмещающими в себя всё, но эти отношения являются раздельным существованием качеств двух связанных сторон $[11$, c. 115$]$.

В «Сюнь-цзы. Ритуал и музыка» написано: «Музыка имеет глубокое влияние на людей, и она оказывает нравственное воздействие на людей очень быстро, поэтому наши предки осмотрительно относились к конкретному выражению музыки. Когда музыка спокойная, люди будут мирно сосуществовать и не развратятся; когда музыка серьёзная и торжественная, люди будут единодушны, а не разобщены. Когда люди мирно сосуществуют и единодушны, армия становится мощной, а оборона городов - прочной, и враг не осмеливается вторгнуться. Таким образом, для простых людей не будет неспокойных мест, они будут любить свою родину и поддерживать 
своего правителя. Затем репутация правителя станет заметной, его влияние расширится, и во всей Поднебесной не будет никого, кто не хотел бы, чтобы он стал их правителем. А это первый шаг к тому, чтобы стать царём! Напротив, когда музыка легкомысленная и злая, люди будут разобщенными и подлыми. Разобщенность может привести к хаосу, а подлость - к борьбе. Хаос и борьба ослабят армию, города перестанут обороняться, и враг вторгнется. Таким образом, простые люди будут неспокойно себя чувствовать на своих местах, не будут любить свою родину, не будут поддерживать своего правителя. Это показывает, что упразднение ритуалов и музыки, возвышение злой музыки - это первопричина ослабления страны, которая влечет за собой унижения и ведёт к смертельной опасности для страны. Вот почему наши предки дорожили ритуалами и музыкой и презирали злую музыку.» [5, с. 170]

\section{3. Констатируюшее сужАение о сошиальной и образовательной функшии музыки}

Суждение Сюнь-цзы о концепции музыки принимает концепцию музыки и все её положения в качестве содержания, объектом его суждения о концепции является музыка, отдельное явление, возврат от особого здесь-существования к универсальности - это и есть констатирующее суждение [11, с. 356]. В «Сюнь-цзы. Ритуал и музыка» говорится: «У людей бывают хорошие и дурные эмоции, и если позволить им получить широкое распространение, и к тому же не отреагировать на это одобрением или гневом и не направить по правильному пути, то возникнет хаос. Наши предки ненавидели такой хаос, поэтому если исправлять поведение людей и их музыку, то в Поднебесной будет стабильность. Траурные одеяния и звуки плача заставляют людские сердца печалиться, надевать доспехи и шлемы и петь в строю, воодушевляют людские сердца; кокетливые наряды, песни царств Чжэн и Вэй развращают людские сердца; царская корона, музыка и танцы «Шао» и «У» делают людей торжественными. Поэтому уши благородного человека не слышат развратной музыки, глаза не смотрят на кокетливые наряды, рот не произносит грязных слов. В отношении этих трёх вещей благородный человек всегда принимает меры предосторожности.» [5, с. 134]

Хотя общество ещё не осознало независимую надежность констатирующего суждения о музыке, но поскольку констатирующее суждение - это всего лишь субъективная особенность, поэтому оно по той же причине или вовсе без причины противостоит противоположному суждению. Таким образом, непосредственная природа музыки прежде всего показывает основу для посредничества между индивидуальностью реальных вещей и их универсальностью. В «Юэ лунь» сказано: «Всякий раз, когда злая музыка заражает людей, мятежные натуры откликаются, мятежная натура проявляется и формирует нравы, возникают хаотичные обычаи и нравы эпохи; когда чистая музыка воздействует на людей, мирные натуры откликаются, мирная натура проявляется и формирует нравы, возникают спокойные обычаи и нравы эпохи. Если кто-то поет, то кто-то обязательно будет подпевать, добро и зло будут следовать за пением, поэтому благородный человек осмотрительно подходит к выбору музыки.» $[5$, с. 158]

Касательно того, что сама музыка должна сохранять свободу, в «Юэ цзи» написано: «Музыка - незаменимый инструмент для урегулирования отношений; ритуал - незаменимый способ управления страной. Музыка делает людей гармоничными и единодушными, ритуал отличает иерархические различия, а принципы ритуала и музыки влияют на внутренний мир человека [7, с. 65]... Изучение человеческой природы и её изменений - это суть музыки, проявление искренности и почтения, устранение лицемерия - вот принципы ритуала [7 , с. 86] ... Благородный человек понимает роль музыки, поэтому при помощи музыки совершенствует тело и воспитывает душу. В годы беспорядков люди меняют местами добро и зло, любят злую музыку и не хотят слушать изящную музыку... Ученики мои, нужно усердно изучать ритуалы и музыку, порочная идея об «антимузыке» ни в коем случае не должна пленить ваши сердца.» [5, с. 186] Он полагал, что музыка сохраняет эту свободу главным образом потому, что содержание музыки объясняется не словами, как в песне, а использует факторы, которые не могут быть усвоены при помощи сознания и понимания. Содержание усваивается в соответствии с его собственным концептуальным значением, выражается так, как оно живет в эмоциях субъекта [6, с. 232]. Поэтому музыка выполняет глубокую общественную функцию и играет значительную образовательную роль.

Одним словом, музыкально-эстетическая мысль Сюнь-цзы продвигает идею о том, чтобы посредством человеческой природы направлять и развивать музыку, его суждения о «музыке» и «ритуале» одинаковы [7, с. 21]. С одной стороны, «лэ» (радость), присущая человеческой природе, направляет музыку, превращая её в «ритуал и музыку». С другой стороны, он выдвигает суждение о здесь-существовании музыки, полагая, что цель музыки больше направляющая, и она заключается в том, чтобы люди «при помощи Дао контролировали желания» [7, с. 23], «сочетали красоту и добро» [7, с. 54], соблюдали этикет и становились благородными людьми. Сюнь-цзы ясно показал образовательную функцию музыки, выдвинул две важные категории: «ритуал и музыка» и «нейтрализация» [10, с. 355] - заметные признаки зрелости. 


\section{ЛИТЕРАТУРА}

1. «Комментарии к «Шо вэнь цзе цзы», Сюй Шэнь (династия Хань), комментарии Дуань Юйцай (династия Цин). Шанхайское издательство древних книг, 1998 год

2. «Комментарии к «Ли цзи», Чжэнь Сюань (династия Хань), комментарии Кун Инда (династия Тан). Шанхайское издательство древних книг, 2008 год

3. «Собрание комментариев к «С шу», Чжу Си (династия Сун), собрание комментариев: книжная компания «Чжунхуа», 2011 год

4. «Пояснения к «Бай ху тун», Чэнь Ли (династия Цин)», пояснения: книжная компания «Чжунхуа», 1994 год

5. История музыкальной эстетики Китая: комментарии к материалам», комментарии Цай Чжундэ, 2007 год

6. «Лекции по истории философии», книга первая (Германия), Гегель, издательство «Коммерческая типография», август 1959 года, 1-е издание

7. «Новая трактовка «Лунъюй», Цянь Му, издательство книжного магазина «Санлянь», март 2005 года, Пекин, 2-е издание

8. «Маленькая логика» (Германия), Гегель, издательство «Коммерческая типография», 1980 год, 2-е издание

9. «Наука логики» (Германия), Гегель, издательство «Коммерческая типография», 1996 год, 1-е издание

10. «Чжуан Лао тун бянь», Цянь Му, издательство книжного магазина «Санлянь», февраль 2005 года, Пекин, 2-е издание

11. «Эстетика», том третий, часть первая (Германия), Гегель, издательство «Коммерческая типография», ноябрь 1979 года, 1-е издание

$$
\text { (с) Хоу Юньлун (13707098756@163.com). }
$$

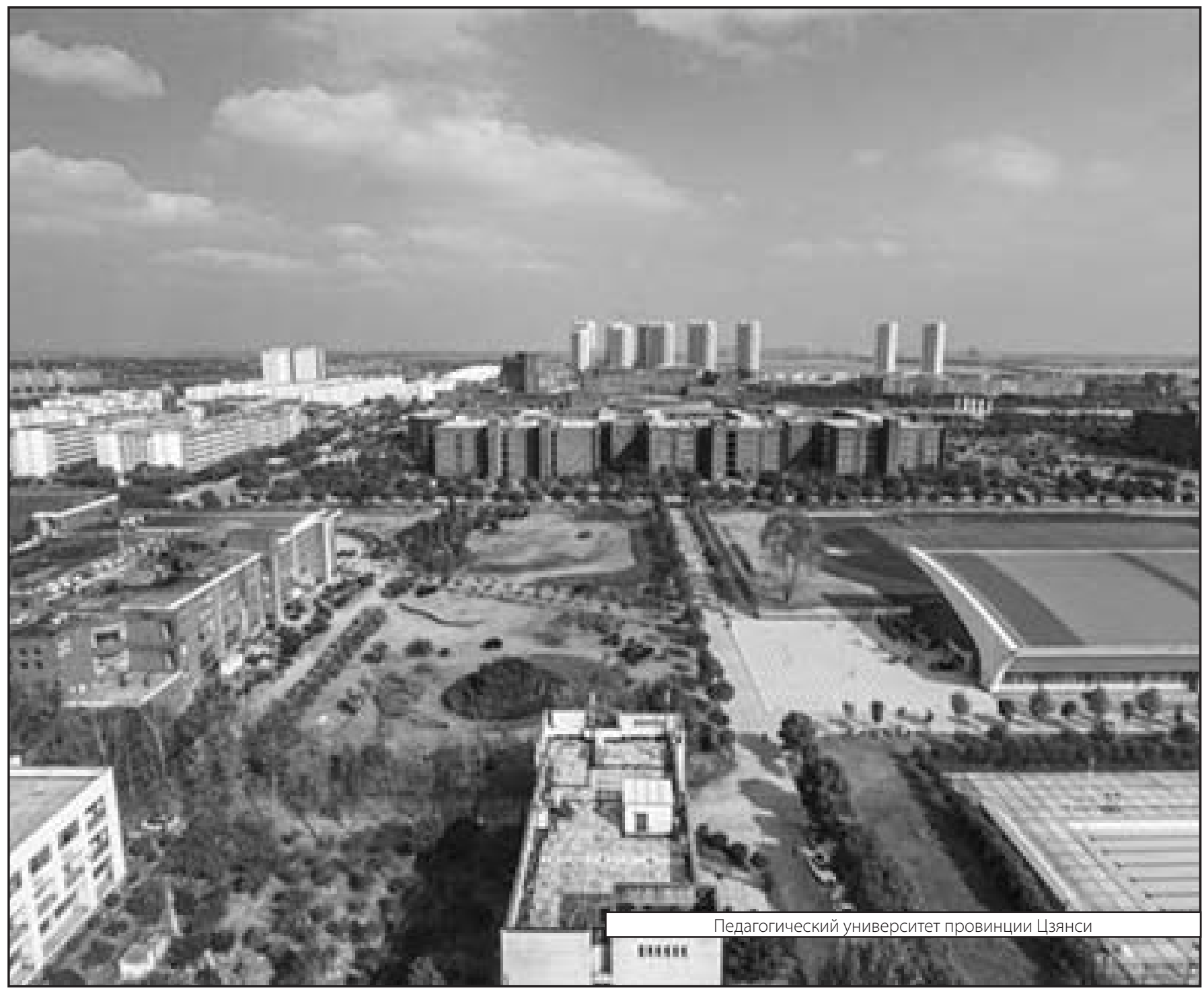

